Jurnal Kesmas Asclepius

Volume 1, Nomor 1, Juni 2019

e-ISSN : 2684-8287

p-ISSN : 2656-8926

DOI: https://doi.org/10.31539/jka.v1i1.523

\title{
HUBUNGAN PENCAHAYAAN DENGAN KELELAHAN MATA PADA PEKERJA TAYLOR
}

\author{
Muhammad Amin ${ }^{1}$, Winti Winiarti ${ }^{2}$, Panzilion $^{3}$ \\ Universitas Muhammadiyah Bengkulu ${ }^{1,2,3}$ \\ maminumb@gmail.com ${ }^{1}$
}

\begin{abstract}
ABSTRAK
Penelitian ini bertujuan untuk mengetahui hubungan antara pencahayaan dengan kelelahan mata pada pekerja Indah Taylor dan Duta Taylor di Kota Bengkulu tahun 2017. Jenis Penelitian yang digunakan adalah diskriptif analitik dengan pendekatan cross sectional. Hasil penelitian bahwa didapatkan bahwa dari 30 responden, sebanyak 8 responden $(26,7 \%)$ yang memiliki pencahayaan memenuhi standar, sebanyak 22 orang $(73,3 \%)$ yang memiliki pencahayaan tidak memenuhi standar Dari 30 responden, sebanyak 20 responden $(66,7 \%)$ yang dinyatakan lelah, $10(33,3 \%)$ responden yang tidak lelah. Hasil analisis bivariat menunjukkan bahwa nilai $\mathrm{p}=0,000$. Simpulan, ada hubungan yang signifikan antara hubungan antara pencahayaan dengan kelelahan mata pada Indah Taylor dan Duta Taylor di Kota Bengkulu tahun 2017.
\end{abstract}

Kata Kunci: Kelelahan Mata, Pencahayaan, Penjahit

\section{ABSTRACT}

This study aims to determine the relationship between lighting and eye fatigue of workers Indah Taylor and Duta Taylor in Bengkulu City in 2017. The type of research used is descriptive analytic with a cross sectional approach. The results showed that of the 30 respondents, as many as 8 respondents (26.7\%) had lighting that met the standards, as many as 22 people (73.3\%) had lighting that did not meet the standards. Of the 30 respondents, 20 respondents (66.7\%) \%) who were declared tired, $10(33.3 \%)$ respondents were not tired. The results of the bivariate analysis showed that the value of $p=0.000$. In conclusion, there is a significant relationship between lighting and eye fatigue for Indah Taylor and Duta Taylor in Bengkulu City in 2017.

Keywords: Eye Fatigue, Lighting, Tailor

\section{PENDAHULUAN}

Tujuan pembangunan kesehatan sebagaimana tercantum dalam Sistem Kesehatan Nasional (SKN) adalah tercapainya kemampuan hidup sehat bagi setiap penduduk agar dapat menunjukkan derajat kesehatan masyarakat yang optimal sebagai salah satu unsur kesejahteraan umum dari tujuan nasional. Pembangunan di sektor industri akhir-akhir ini terus meningkat, baik industri besar, sedang maupun kecil. Pembangunan di sektor industri ditujukan untuk memperluas lapangan kerja, kesempatan berusaha dan untuk meningkatkan mutu serta perlindungan bagi tenaga kerja. Perlindungan tenaga kerja ditujukan kepada perbaikan upah, syarat kerja, serta jaminan sosial lainnya dalam rangka perbaikan kesejahteraan tenaga kerja (Suma'mur, 2007). 
Keselamatan dan Kesehatan Kerja (K3) adalah salah satu bentuk upaya untuk menciptakan tempat kerja yang aman, sehat, bebas dari pencemaran lingkungan, sehingga dapat melindungi dan bebas dari kecelakaan kerja pada akhirnya dapat meningkatkan efisiensi dan produktivitas kerja. Dalam setiap kegiatan proses pekerjaan, faktor yang perlu diperhatikan adalah pencahayaan. Oleh karena itu keadaan terang optimum sangat diharapkan agar tenaga kerja dapat bekerja dengan baik (Silalahi, 2005).

Salah satu sektor industri yang mengalami perkembangan pesat yaitu industri konveksi. Dalam pengerjaannya, konveksi membutuhkan pekerja yang banyak. Dalam rangka memenuhi target dan pangsa pasar, mulai dari desain-desain yang berbeda, bahan baku yang berkualitas sampai pada keanekaragaman produk yang terus menerus disesuaikan dengan kebutuhan masyarakat. Dalam industri konveksi yang notabene aktifitas kerjanya adalah menjahit, maka dapat dipastikan bahwa peran penerangan atau kualitas penglihatan yang baik mempengaruhi jalananya proses aktivitas menjahit tersebut, untuk mendapatkan hasil yang baik maka, pekerjaan menjahit juga harus dilakukan dengan teliti dan baik (Riduan, 2014).

Menjahit merupakan pekerjaan yang membutuhkan organ mata dan konsentrasi tinggi untuk melihat secara kontinue benda-benda kecil maupun benda besar. Mata dibentuk untuk menerima rangsangan berkas-berkas cahaya pada retina selanjutnya dengan perantaraan serabut-serabut nervus optikus, mengalihkan rangsangan ini ke pusat penglihatan pada otak untuk ditafsirkan. Kelelahan mata dapat terjadi apabila ada gangguan yang dialami mata karena otot -ototnya yang dipaksa bekerja keras terutama saat harus melihat obyek dekat dalam jangka waktu yang lama (Guyton \& Hall, 2007).

Mata juga merupakan organ penglihatan dan sangat sensitif terhadap cahaya karena terdapat photocereptor inpuls saraf dari stimulasi photocereptor dibawa ke otak pada lobus oksipital di serebrum dimana sensasi penglihatan diubah menjadi persepsi. Reseptor penglihatan dapat merespons satu juta stimulus yang berbeda setiap detik dari sumber penerangan (Guyton \& Hall, 2007).

Penerangan merupakan salah satu faktor untuk mendapatkan keadaan lingkungan kerja yang aman dan nyaman, serta mempunyai kaitan yang sangat erat dengan meningkatnya produktivitas (Prayoga et al., 2014).

Penerangan yang baik memungkinkan tenaga kerja melihat obyek yang dikerjakannya secara jelas, cepat, dan nyaman. Lebih dari itu penerangan yang memadai memberikan kesan pemandangan yang lebih baik dan keadaan yang menyegarkan. Sebaliknya jika lingkungan kerja memiliki penerangan yang buruk dapat berakibat sebagai berikut yaitu kelelahan mata dengan berkurangnya daya dan efisiensi kerja, kelelahan mental, keluhan pegal-pegal di daerah mata, dan sakit kepala di sekitar mata, kerusakan alat penglihatan dan dapat meningkatnya kecelakaan saat kerja (Puha et al., 2014).

Hal di atas selaras dengan data dari Internasional Labour Organization (2013) menunjukkan setiap tahun ada lebih dari 250 juta kecelakaan di tempat kerja dan lebih dari 160 juta pekerja menjadi sakit karena bahaya di tempat kerja. Terlebih lagi 1,2 juta pekerja meninggal akibat kecelakaan dan sakit di tempat kerja.

Sesuai dengan Keputusan Menteri Kesehatan No. 1405 tahun 2002, tentang Persyaratan Lingkungan Kerja Industri, Pencahayaan di ruangan, untuk jenis kegiatan pekerjaan rutin, seperti pekerjaan kantor atau administrasi, ruang kontrol, pekerjaan mesin dan perakitan atau penyusun tingkat pencahayaan minimalnya adalah 300 Lux. 
Adapun tingkat penerangan atau NAB (Nilai Ambang Batas) untuk pekerjaan menjahit adalah 200 lux (UU no 23 1992).

Beberapa faktor yang dapat mempengaruhi penglihatan menurut Dyer \& Morris (1990) adalah utama karena faktor usia. Dengan bertambahnya usia menyebabkan lensa mata berangsur-angsur kehilangan elastisitasnya, dan agak kesulitan melihat pada jarak dekat (Ramadhani, 2012).

Menurut Grandjean (1988) silau adalah suatu proses adaptasi yang berlebihan pada mata sebagai akibat dari retina terkena sinar yang berlebihan. Selanjutnya faktor ukuran pupil. Agar jumlah sinar yang diterima oleh retina sesuai, maka otot iris akan mengatur ukuran pupil. Lubang pupil juga dipengaruhi oleh memfokusnya lensa mata, mengecil ketika lensa mata memfokus pada objek yang dekat. Faktor sudut dan ketajaman penglihatan. Sudut penglihatan (visual angle) didefinisikan sebagai sudut yang berhadapan dengan objek pada mata (Suma'mur, 2009).

Kelelahan mata merupakan salah gangguan yang dialami mata karena otot-ototnya dipaksa bekerja keras terutama saat harus melihat objek dekat dalam jangka waktu lama (Puha et al., 2014). Kelelahan mata adalah ketegangan pada mata yang disebabkan oleh penggunaan indera penglihatan dalam jangka waktu yang lama, biasanya disertai dengan kondisi pandangan yang tidak nyaman (Riduan, 2014).

Kelelahan mata dikenal sebagai tegang mata atau astenophia yaitu kelelahan ocular atau ketegangan pada organ visual dimana terjadi gangguan pada mata dan sakit kepala berhubungan dengan penggunaan mata secara intensif. Keletihan visual menggambarkan seluruh gejala-gejala yang terjadi sesudah stres berlebihan terhadap setiap fungsi mata, diantaranya adalah tegang otot siliaris yang berakomodasi saat memandang objek yang sangat kecil dalam jarak yang sangat dekat, kelelahan mata juga terjadi karena penerangan tempat kerja yang kurang optimal (Siswanto, 2009).

Kelelahan mata akibat kelelahan kerja dapat didefenisikan yaitu suatu mekanisme perlindungan tubuh agar tubuh terhindar dari kerusakan lebih lanjut sehingga terjadi pemulihan setelah istirahat. Kelelahan kerja merupakan kriteria yang lengkap tidak hanya menyangkut kelelahan yang bersifat fisik dan psikis saja tetapi lebih banyak kaitannya dengan adanya penurunan kinerja fisik, adanya perasaan lelah, penurunan motivasi, dan penurunan produktivitas kerja. Kelelahan kerja dapat terjadi akibat dari faktor lingkungan kerja, faktor individu dan faktor pekerjaannya (Tarwaka, 2014; Notoatmodjo, 2010).

Berdasarkan hasil penelitian dari Puha et al., (2014) kelelahan mata yang diakibatkan oleh pencahayaan yang tidak sesuai dengan standarnya dan juga usia tua menunjukkan 42 responden yang terdiri dari tingkat kelelahan mata yang mengalami kelelahan mata ringan sebanyak 30 orang $(71,43 \%)$ dan responden yang memiliki tingkat kelelahan mata berat yaitu sebanyak 12 orang $(28,57 \%)$.

Berdasarkan hasil observasi pada beberapa taylor terbesar di kota Bengkulu, peneliti memilih Duta Taylor dan Indah Taylor sebagai tempat penelitian dikarenakan pada maing-masing ruangan Duta Taylor dan Indah Taylor tidak sama pencahayannya. Ada ruangan yang lampunya redup dan ada juga yang lampunya terlalu terang dikarenakan memiliki pekerjaan banyak ruangan tertutup dan tidak ada cahaya yang masuk jika tidak menggunakan lampu. Peneliti melakukan pengukuran di 2 titik pada Indah taylor yang hasilnya 51,6 lux dan 3 titik pada Duta taylor 55,9 lux. Selain itu penjahit juga mengatakan bahwa mata mereka cepat mengalami kelelahan dan hasil wawancara kepada 5 orang penjahit bahwa mereka mengalami mata perih, berair, dan mata terlihat sayu. 


\section{METODE PENELITIAN}

Jenis penelitian ini menggunakan penelitian non experimental, dengan metode observasional analitik, yaitu menjelaskan hubungan antara variabel-variabel melalui pengujian hipotesis yang dirumuskan sebelumnya. Metode yang digunakan adalah survei dengan pendekatan cross-sectional karena variabel sebab (intensitas penerangan) dan akibat (kelelahan mata) yang terjadi pada objek penelitian diukur atau dikumpulkan dalam waktu yang bersamaan dan dilakukan pada situasi yang sama.

Analisis data yang digunakan adalah analisis univariat dan analisis bivariat. Analisis univariat bertujuan untuk mengetahui distribusi frekuensi dan karakteristik responden, intensitas penerangan, dan kelelahan mata. Analisis bivariat adalah uji hipotesis antara dua variabel, yakni variabel bebas (intensitas penerangan) dan variabel terikat (kelelahan mata). Teknik pengolahan dan analisis data dilakukan dengan uji statistik chi-square.

Sampel dalam penelitian ini adalah para pekerja penjahit, teknik pengambilan sampel yang digunakan dalam penelitian ini diambil dengan menggunakan total sampling yaitu seluruh populasi di tempat pekerja penjahit dijadikan sampel. Sampel dalam penelitian ini yaitu penjahit yang bekerja di Indah taylor, terdapat 20 orang penjahit dan pada Duta taylor terdapat 10 penjahit dengan waktu penelitian dilaksanakan selama satu bulan yaitu pada tanggal 30 Juni -31 Juli 2017.

Penelitian dilakukan dengan dua cara yaitu observasi dan wawancara. Observasi dilakukan dengan melakukan pengukuran dan pencatatan. Pengukuran dalam penelitian ini menggunakan alat lux meter yang digunakan untuk mengukur penerangan setempat (lokal illumination) dan penerangan umum (general illumination), sedangkan pencatatan dilakukan dengan menggunakan lembar observasi. Wawancara dilakukan dengan menggunakan kuesioner tentang kelelahan mata.

\section{HASIL PENELITIAN}

Analisis Unvariat

Tabel. 1

Distribusi frekuensi berdasarkan jenis kelamin, pendidikan, umur dan masa kerja penelitian ini

\begin{tabular}{lccc}
\hline Variabel penelitian & kategori & Jumlah & $(\%)$ \\
\hline Jenis Kelamin & Laki-laki & 18 & 60 \\
& Perempuan & 12 & 40 \\
\hline & Total & 30 & 100 \\
\hline Pendidikan & SMP & 14 & 46,66 \\
& SMA & 16 & 53,34 \\
& PT & - & - \\
\hline \multirow{2}{*}{ Umur } & Total & 30 & 100 \\
& $<20$ Tahun & 1 & 3 \\
& 20-40 Tahun & 26 & 87 \\
& $>40$ Tahun & 3 & 10 \\
\hline Masa kerja & total & 30 & 100 \\
& $<1$ Tahun & 3 & 10 \\
& 1-5 Tahun & 12 & 40 \\
& $>5$ tahun & 15 & 50 \\
\hline
\end{tabular}


Dari tabel 1 diketahui bahwa karakteristik responden berdasarkan jenis kelamin dari 30 jumlah responden, yang paling dominan adalah laki-laki yaitu sebanyak 18 (60\%) dengan latar belakang pendidikan sebagian besar sebanyak $16(53,34 \%)$ orang responden berpendidikan SMA, dan umur responden sebagian besar berkisar antara 2040 tahun dengan jumlah 26 orang (87\%), dengan masa kerja 1-5 tahun berjumlah 15 orang $(50 \%)$.

Tabel.2

Distribusi Frekuensi Pencahayaan dan kelelahan mata Pada Pekerja Indah Taylor dan Duta Taylor

\begin{tabular}{clcc}
\hline Variabel Penelitian & \multicolumn{1}{c}{ Kategori } & Frekuensi & $\%$ \\
\hline \multirow{2}{*}{ Pencahayaan } & Memenuhi standar & 8 & 26,7 \\
& Tidak memenuhi standar & 22 & 73,3 \\
\hline \multirow{2}{*}{ Kelelahan Mata } & Total & 30 & 100 \\
& Lelah & 20 & 66,7 \\
& Tidak lelah & 10 & 33,3 \\
\hline & Total & 30 & 100 \\
\hline
\end{tabular}

Berdasarkan tabel 2 menunjukkan bahwa dari 30 responden sebanyak 22 orang $(73,3 \%)$ yang memiliki pencahayaan tidak memenuhi standar dan dari 30 responden tersebut sebanyak 20 responden $(66,7 \%)$ yang dinyatakan mengalami kelelahan mata.

\section{Analisis Bivariat}

Tabel. 3

Hubungan Antara pencahayaan dengan kelelahan mata pada pekerja Indah Taylor dan Duta Taylor

\begin{tabular}{|c|c|c|c|c|c|c|c|}
\hline \multirow{3}{*}{ Pencahayaan } & \multicolumn{6}{|c|}{ Kelelahan mata } & \multirow{3}{*}{$\begin{array}{c}\text { P- } \\
\text { Value }\end{array}$} \\
\hline & \multicolumn{2}{|c|}{ Tidak Lelah } & \multicolumn{2}{|c|}{ Lelah } & \multicolumn{2}{|c|}{ Total } & \\
\hline & $\mathrm{n}$ & $\%$ & $\mathrm{n}$ & $\%$ & $\mathrm{n}$ & $\%$ & \\
\hline Sesuai syarat & 7 & 87,5 & 1 & 12.5 & 8 & 100 & \\
\hline Tidak sesuai & & & & & & & 0,000 \\
\hline sayarat & 3 & 23,6 & 19 & 86,4 & 2 & 100 & \\
\hline Total & 10 & 33,3 & 20 & 66,7 & 10 & 100 & \\
\hline
\end{tabular}

Berdasarkan tabel 3 menunjukan hubungan antara pencahayaan dengan kelelahan mata. Pada Pekerja Indah Taylor dan Duta Taylor di kota Bengkulu tahun 2017 dengan hasil uji pearson chi-square didapat nilai exact.sig $(\mathrm{P})=0,000$. Karena nilai $\mathrm{P}<\alpha 0,05$ dengan tingkat kepercayaan $95 \%$ dan tingkat kesalahan $(\alpha)$ yang digunakan yaitu $5 \%$ maka ada hubungan antara pencahayaan dengan kelelahan mata pada pekerja Indah Taylor dan Duta Taylor di kota Bengkulu tahun 2017

\section{PEMBAHASAN}

Berdasarkan hasil penelitian pencahayaan 30 responden, sebanyak 8 responden $(26,7 \%)$ yang memiliki pencahayaan memenuhi standar, sebanyak 22 orang $(73,3 \%)$ yang memiliki pencahayaan tidak memenuhi standar.

Mayoritas lampu pada Indah dan Duta Taylor menggunakan lampu neon berdaya 20 watt. Daya lampu sebesar 20 watt ini masih belum bisa mencukupi kebutuhan intensitas penerangan setempat mengingat dinding, langit-langit, dan lantai di sana masih dalam kondisi gelap dan kotor. Hal inilah yang menyebabkan intensitas penerangan setempat tidak memenuhi standar karena warna dinding, langit-langit, dan 
lantai yang gelap dapat menurunkan efektivitas dari instalasi penerangan sebanyak $50 \%$ (Siswanto, 2009). Sehingga tegangan lampu yang awalnya 20 watt, akan menjadi semakin kecil karena mengalami penurunan sebesar 50\%.

Keadaan lampu semua terlihat kurang perawatan, keadaan lampu yang sudah termasuk dalam kategori sedang, lambat laun akan menjadi kotor. Mengingat komposisi warna yang dihasilkan lampu neon tergantung zat-zat fluorescent yang melapisi bagian dalam lampu tersebut (Silalahi, 2005). Keadaan lampu bagian luar yang kotor ini pun akhirnya juga akan menghalangi intensitas penerangan yang dihasilkan oleh lampu tersebut. Hal itulah yang menyebabkan pencahayaan pada Duta Taylor dan Indah taylor tidak memenuhi standar.

Pencahayaan baik yang tinggi, rendah, maupun yang menyilaukan berpengaruh terhadap kelelahan mata maupun ketegangan saraf para pekerja yang pencahayaan tempat kerjanya tidak memadai atau tidak sesuai standar. Faktor yang sangat menentukan dalam pencahayaan adalah ukuran objek, derajat kontras antara objek dan sekelilingnya, luminensi dari lapangan penglihatan, yang tergantung dari pencahayaan dan pemantulan pada arah si pengamat, serta lamanya melihat (Anizar, 2009).

Berdasarkan hasil penelitian dapat dilihat bahwa banyak terdapat penjahit yang mengalami kelelahan mata. Kelelahan mata adalah lelahnya otot-otot mata akibat penggunaan mata untuk melihat dengan jarak dekat, berkonsentrasi, atau, terlalu fokus pada objek yang cenderung tidak nyaman untuk dilihat dalam kurun waktu yang lama (Suma'mur, 2007). Selain itu, kelelahan mata disebabkan oleh stres yang terjadi pada fungsi penglihatan. Stres pada otot yang berfungsi untuk akomodasi dapat terjadi pada saat seseorang berupaya untuk melihat pada objek yang berukuran kecil dan pada jarak yang dekat dalam jangka waktu yang relative lama. Pada kondisi seperti itu, otot-otot mata akan bekerja secaraterus-menerus dan lebih dipaksakan (Guyton, 2007).

Hasil uji statistik didapatkan bahwa ada hubungan yang signifikan antara hubungan antara pencahayaan dengan kelelahan mata pada Indah Taylor dan Duta Taylor di kota Bengkulu tahun 2017 dengan $p$ value $=0,000$.

Keselamatan dan Kesehatan Kerja (K3) adalah salah satu bentuk upaya untuk menciptakan tempat kerja yang aman, sehat, bebas dari pencemaran lingkungan, sehingga dapat melindungi dan bebas dari kecelakaan kerja pada akhirnya dapat meningkatkan efisiensi dan produktivitas kerja. Dalam setiap kegiatan proses pekerjaan, faktor yang perlu diperhatikan adalah pencahayaan. Oleh karena itu keadaan terang optimum sangat diharapkan agar tenaga kerja dapat bekerja dengan baik (Silalahi, 2005).

Upaya kesehatan bagi tiap individu perlu dijaga dan ditingkatkan di manapun individu itu berada, tidak terkecuali ditempat kerja, karena di tempat kerja terdapat berbagai macam faktor fisik yang dapat menyebabkan kecelakaan kerja dan penyakit akibat kerja. Salah satu faktor fisik yang ada di tempat kerja yaitu penerangan (Riduan, 2014).

Mata merupakan salah satu organ tubuh yang paling penting. Dalam fungsinya untuk melihat harus tidak dihadapkan pada beban tambahan seperti penerangan obyek yang kurang intensitasnya sesuai dengan keperluan. Oleh karena mata meliput daerah yang lebih luas, dapat mendeteksi tingkat cahaya yang sangat minim dalam pandangan malam hari. Berdasarkan kondisi-kondisi inilah, mata seringkali lebih cepat mengalami kelelahan (Nurmianto, 1996).

Kelelahan mata merupakan salah gangguan yang dialami mata karena otot-ototnya dipaksa bekerja keras terutama saat harus melihat objek dekat dalam jangka waktu lama 
(Puha et al., 2014). Kelelahan mata adalah ketegangan pada mata yang disebabkan oleh penggunaan indera penglihatan dalam jangka waktu yang lama, biasanya disertai dengan kondisi pandangan yang tidak nyaman (Riduan, 2014).

Kelelahan mata dikenal sebagai tegang mata atau astenophia yaitu kelelahan ocular atau ketegangan pada organ visual dimana terjadi gangguan pada mata dan sakit kepala berhubungan dengan penggunaan mata secara intensif. Keletihan visual menggambarkan seluruh gejala-gejala yang terjadi sesudah stres berlebihan terhadap setiap fungsi mata, diantaranya adalah tegang otot siliaris yang berakomodasi saat memandang objek yang sangat kecil dalam jarak yang sangat dekat, kelelahan mata juga terjadi karena penerangan tempat kerja yang kurang optimal (Siswanto, 2009).

Kelelahan kerja merupakan bagian dari permasalahan umum yang sering dijumpai pada tenaga kerja. Menurut beberapa peneliti, kelelahan secara nyata dapat mempengaruhi kesehatan tenaga kerja dan dapat menurunkan produktivitas (Silalahi, 2005).

Tingkat kelelahan akibat kerja yang dialami pekerja dapat menyebabkan ketidaknyamanan, gangguan dan mengurangi kepuasan serta penurunan produktivitas yang ditunjukkan dengan berkurangnya kecepatan performansi, menurunnya mutu produk, hilangnya orisinalitas, meningkatnya kesalahan dan kerusakan, kecelakaan yang sering terjadi, kendornya perhatian dan ketidaktepatan dalam melaksanakan pekerjaan. Kelelahan kerja dapat terjadi akibat dari faktor lingkungan kerja, faktor individu dan faktor pekerjaannya. Masalah yang berkaitan dengan kelelahan kerja tersebut banyak dijumpai pada industri konveksi kecil dan menengah, dimana pekerjanya bekerja dengan gerakan yang sama dan berulang dalam waktu lama (Puha et al., 2014).

Hasil penelitian ini sejalan dengan penelitian yang dilakukan oleh Suryani et al., (2002) yang menyatakan bahwa terdapat hubungan yang sangat kuat (positif) antara tingkat pencahayaan dengan kelelahan mata.

Hasil penelitian ini juga sama dengan penelitian yang dilakukan oleh Alamsyah (2009) yang menyatakan dari hasil perhitungan didapatkan nilai P-value sebesar 0,000 yang menunjukkan bahwa terdapat hubungan yang sangat kuat antara keluhan kelelahan mata dengan intensitas penerangan.

Hal ini sejalan dengan penelitian yang dilakukan oleh (Rahim, 2014) mendapatkan Pvalue 0,11>0,05 yang berarti ada hubungan antara tingkat pencahayaan dengan keluhan kelelahan mata yaitu dari 33 meja kerja yang diukur tingkat pencahayaannya, terdapat 7 meja yang memiliki tingkat pencahayaan yang sesuai dengan standar yang diajukan. Pencahayaan dengan intensitas yang rendah dapat menyebabkan kelelahan mata, ketegangan mata, dan keluhan pegal di sekitar mata. Namun apabila intensitas pencahayaan tinggi, hal ini juga dapat menimbulkan kelelahan mata, kesilauan yang dapat mengganggu pekerjaan.

Menurut (Budiono, 2013) adapun upaya yang dapat dilakukan untuk mengatasi kelelahan pada mata penjahit yaitu

\section{Mengalihkan Perhatian}

Yang perlu di lakukan adalah mengalihkan fokus selama 20 detik pada beberapa objek lain. Ini merupakan salah satu cara terbaik dan paling sederhana untuk mengatasi ketegangan pada mata.

\section{Mengedipkan Mata Berulang Kali}


Hal ini bisa meregangkan otot mata yang tegang. Terlalu lama menatap komputer membuat mata kering dan lelah. Dengan mengedipkan mata, anda bisa membasahi mata secara teratur.

\section{Olahraga Mata}

Latihan otot mata bisa meringankan rasa lelah pada penglihatan lakukan sedikti perenggangan pada mata seperti menggerakkan mata, berkedip atau pun mengalihlan fokus.

\section{Pijat Kelopak Mata}

Pijat kelopak mata dan otot-otot di sekitarnya dengan lembut. Ini termasuk cara melakukan relaksasi dan meningkatkan sirkulasi. Pijatan ini juga merangsang kelenjar air mata, yang mencegah kekeringan pada mata.

\section{Perawatan Mata}

Mata lelah juga bisa dicegah dengan perawatan mata, di antaranya mengompres mata dengan kain yang sudah dibasahi air hangat. Mata membutuhkan waktu untuk beristirahat sejenak. Luangkan sedikit waktu untuk melakukan relaksasi pada mata.

\section{SIMPULAN}

Hasil penelitian yang dilakukan di Indah Taylor dan Duta Taylor dapat disimpulkan bahwa:

Dari 30 responden, sebanyak 8 responden yang memiliki pencahayaan memenuhi standar, sebanyak 22 orang yang memiliki pencahayaan tidak memenuhi standar. Dari 30 responden, sebanyak 20 responden yang dinyatakan lelah, 10 responden yang tidak lelah. Ada hubungan yang signifikan antara hubungan antara pencahayaan dengan kelelahan mata pada pekerja Indah Taylor dan Pekerja Duta Taylor di kota Bengkulu tahun 2017 dengan $\mathrm{p}$ value $=0,000$.

\section{SARAN}

\section{Bagi pemilik usaha}

Mengingat pencahayaan dapat berpengaruh terhadap kelelahan mata, kepada pihak Duta dan Indah taylor untuk dapat memberikan pencahayaan yang memenuhi standar yaitu 200 Lux, agar tidak terjadinya kelelahan mata pada pekerja.

Untuk mengurangi terjadinya faktor-faktor yang menyebabkan kelelahan fisik dan menurunnya produktivitas pada pekerja indah taylor dan duta taylor, kepada pihak pemilik usaha untuk memberikan kursi yang memenuhi standar khusus untuk penjahit pada pekerja agar berkurangnya kelelahan fisik bagi pekerja.

Untuk pekerja yang sering mengalami kelelahan mata akibat pencahayaan yang buruk pada saat bekerja, maka kepada pihak Indah Taylor dan Duta Taylor untuk melakukan pemeriksaan mata secara periodik.

\section{Bagi Pekerja}

Setiap pekerja sebaiknya mendapat pencahayaan yang memenuhi standar (200 lux). Jika pekerja merasakan keluhan kelelahan mata seperti mata merah, mata terasa pedih, sakit kepala, dan lain sebagainya. Disarankan untuk melakukan relaksasi atau mengistirahat mata.

\section{Peneliti Selanjutnya}


Diharapkan di masa yang akan datang dapat digunakan sebagai salah satu sumber data untuk penelitian selanjutnya dan dilakukan penelitian lebih lanjut berdasarkan faktor- faktor lainnya, variabel yang berbeda, jumlah sampel yang lebih banyak, tempat yang berbeda, dan penelitian yang lebih akurat dan tepat yang berhubungan dengan pencahayaan dan kelelahan mata.

\section{DAFTAR PUSTAKA}

Alamsyah, R. M. (2009). Faktor-Faktor yang Mempengaruhi Kebiasaan Merokok dan Hubungan dengan Status Penyakit Periodontal Remaja Medan 2007. Universitas Sumatera Utara Medan

Anizar, A. (2009). Teknik Keselamatan dan Kesehatan Kerja di Industri. Yogyakarta: Graham Ilmu

Budiono, P. (2013). Bunga Rampai Hiperkes dan Kk. Semarang: Badan Penerbit Universitas Diponegoro

Dyer, H., \& Morris, A. (1990). Human Aspects of Library Automation. England: Gower Publishing

Grandjean, E. (1988). Fitting the Task to the Man (4th Ed.). London : Taylor \& Francis Inc

Guyton, A. C., \& Hall, J. E. (2007). Buku Ajar Fisiologi Kedokteran. Edisi ke-11. Jakarta: EGC

International Labour Organization, (2013). Keselamatan dan Kesehatan Kerja Sarana untuk Produktivitas. Jakarta: Score (Online) http://www.ilo.org Diakses 26 April 2018

Notoatmodjo, S. (2010). Kesehatan Masyarakat Ilmu dan Seni. Jakarta: PT. Rineka Cipta

Nurmianto, E. (1996). Ergonomi : Konsep Dasar dan Aplikasinya. Surabaya: Guna Widya

Prayoga, H. A., Irwan, B., \& Evi, W. (2014). Hubungan antara Intensitas Pencahayaan dan Kelainan Refraksi Mata dengan Kelelahan Mata pada Tena para Medis di bagian Rawat Inap RSUD dr. Soedirman Mangun Sumarso Wonogiri. Unnes Journal of Public Health, 3(4)

Puha, T. N., Rattu, J., \& Kawatu. (2014). Hubungan Intensitas Pencahayaan dengan Kelelahan Mata pada Pekerja Penjahit Sektor Usaha Informal di Kompleks Gedung Presiden Pasar 45 Kota Manado. Universitas Sam Ratu langi Manado

Rahim, A. (2014). Faktor-Faktor yang Berhubungan Gejala Kelelahan Mata (Asstenopia) pada Karyawan Pengguna Komputer PT. Grapari Telkomsel Kota Kendari. Jurnal Ilmiah Fakultas Kesehatan Masyarakat Universitas Halu Oleo Kendari

Ramadhani, A. F. (2012). Analisis Tingkat Pencahayaan dan Keluhan Kelelahan Mata pada Pekerja di Area Produksi Pelumas Jakarta PT. Pertamina (Persero) Tahun 2012. Universitas Indonesia

Riduan, R. (2014). Keselamatan Kerja dan Pencegahan Kecelakaan. Jakarta: CV Haji Masagung

Silalahi, M. A. (2005). Studi tentang Ilmu Administrasi Konsep, Teori dan Dimensi. Bandung: Sinar Baru

Siswanto, S. (2009). Manajemen Tenaga Kerja Indonesia, Edisi: Jakarta: PT. Bumi Aksara 
Suma'mur, S. (2007). Keselamatan Kerja dan pencegahan Kecelakaan. Jakarta: CV Haji Masagung

Suryani, A. I. Sailah, S., \& Hambali, E. (2002). Pengantar Teknologi Emulsi. Departemen Teknologi Industri Pertanian, Fateta, IPB. Bogor

Tarwaka, T. (2014). Dasar-Dasar Keselamatan Kerja serta Pencegahan Kecelakaan di Tempat Kerja. Harapan Press. Surakarta

Undang-Undang Nomor 23 Tahun 1992 tentang Kesehatan 